\title{
KAKSA Orang Tua Siswa TK : Komunitas Anti Kekerasan Seksual pada Anak
}

\author{
Ira Paramastri ${ }^{1}$ \\ Fakultas Psikologi Universitas Gadjah Mada
}

\begin{abstract}
Currently, primary prevention efforts for child sexual abuse (CSA) are mostly done as general education program for children at school. The program is criticized for placing responsibility of child protection solely on the children and rarely involves family, community, and children's surrounding neighborhood. This study aimed to examine CSA psychoeducational prevention toward kindergarteners parents' knowledge after an intervention in form of psychoeducational leaflets and booklets. The study was quasiexperimental study with the one group pretest-posttest design. Twenty six parents of kindergarteners participated in the study. Instruments used for the study was CSA knowledge test. Quantitative analysis was used to describe the difference of kindergarteners parents' knowledge before and after the program $(\mathrm{p}=0.006, \mathrm{p}<0.05)$. Psychoeducation with booklet and leaflet was able to improve kindergarteners parents' knowledge on CSA prevention.
\end{abstract}

Keywords: child sexual abuse psychoeducational prevention; KAKSA; kindegarteners parents' knowledge

\begin{abstract}
Abstrak. Saat ini, upaya prevensi primer terhadap kekerasan seksual pada anak (KSA) yang banyak dilakukan adalah program edukasi umum yang ditujukan untuk anak dilakukan di sekolah. Program ini dikritik karena hanya menempatkan tanggung jawab perlindungan pada anak dan jarang melibatkan keluarga, komunitas, dan lingkungan tempat tinggal anak. Tujuan penelitian ini adalah menguji psikoedukasi prevensi KSA terhadap peningkatan pengetahuan orang tua siswa TK setelah mendapat intervensi melalui psikoedukasi disertai liflet \& booklet. Penelitian ini merupakan penelitian eksperimen kuasi dengan the one group pretest-posttest design. Sebanyak 26 orang tua siswa TK terlibat dalam penelitian. Instrumen penelitian yang digunakan adalah tes pengetahuan KSA. Analisis data kuantitatif dilakukan untuk menguji perbedaan pengetahuan orang tua siswa TK sebelum-sesudah intervensi. Hasil penelitian menunjukkan perbedaan pengetahuan orang tua siswa TK sebelum dan sesudah program $(p=0,006, p<0,05)$. Psikoedukasi disertai buklet dan liflet dapat meningkatkan pengetahuan orang tua siswa TK tentang prevensi KSA.
\end{abstract}

Kata kunci: KAKSA; pengetahuan orang tua siswa TK; psikoedukasi prevensi kekerasan seksual pada anak

Berdasarkan Global Status Report on Violence Prevention yang dilakukan oleh WHO menyebutkan bahwa satu dari lima perempuan di dunia mengalami kekeras- -an seksual dan sepertiganya dilakukan oleh kerabat dekatnya (Butchart \& Mikton, 2014).

Data di Indonesia mengacu pada

\footnotetext{
1 Korespondensi mengenai isi artikel ini dapat dilakukan melalui ira_paramastri@ugm.ac.id
} 
Komnas Perempuan (2016) menyatakan bahwa kekerasan seksual merupakan kasus kedua yang sering terjadi, sedangkan menurut Badan Pemberdayaan Perempuan dan Masyarakat (BPPM) (2016) kasus kekerasan seksual pada anak merupakan kasus yang paling banyak ditangani di tahun 2014-2015 yaitu sebesar $56 \%-63 \%$ dari total kasus kekerasan pada anak (KSA). Berdasarkan WHO (2016) menyatakan bahwa satu kasus KSA diramalkan dapat mewakili 75 kasus KSA yang tidak terlaporkan. Prevalensi korban perempuan lebih banyak daripada korban laki-laki dan terjadi pada negara dengan penghasilan menengah ke bawah.

Kekerasan seksual pada anak (KSA) adalah penyalahgunaan kekuasaan yang dilakukan orang yang lebih tua, kuat dan berpengetahuan dari anak untuk memuaskan kepuasan emosi dan seksual. KSA merupakan perbuatan fisik dan psikologis. Perbuatan fisik, yaitu kekerasan terhadap anak melibatkan sentuhan dan non sentuhan. Sebagai pengalaman psikologis dimaksudkan bahwa kekerasan pada anak merepresentasikan penyalahgunaan kekuasaan dan otoritas. Pelaku memuaskan kepuasan emosional dan seksualnya, dan anak-anak terluka serta mengalami kebingungan (WHO, 2016 ; Children's Bureau, 2016 ; Goodyear, 2012 ; United Nations, 2009).

KSA dapat mengakibatkan trauma fisik, mental, sosial, maupun perilaku (Gaskill \& Perry, 2012). Selanjutnya, KSA mempunyai dampak jangka pendek maupun jangka panjang. Briere dan Runtz (dalam Filkelhor, 2005) menemukan bahwa orang dewasa yang mengalami KSA diprediksi akan mengalami masalah emosional dan perilaku di sepanjang kehidupannya. Anak yang memiliki pengalaman KSA dalam waktu yang lama dapat menyebabkan rendahnya selfesteem, perasaan tidak berharga, pandangan yang buruk terhadap seks. Anak juga menjadi pendiam dan curiga terhadap orang dewasa, dan tertekan dalam kehidupannya. Anak tidak dapat konsentrasi pada pekerjaan dan tugastugas yang lain (Freyd et al, 2005).

Filkelhor (2005) menyebutkan bahwa KSA akan memberikan dampak yang bervariasi pada kepribadian anak antara lain reaksi emosi, persepsi diri, reaksi fisik dan somatis, seksualitas, dan hubungan sosial. Efek dari KSA (misalnya kecemasan, depresi, perilaku agresif, perilaku menarik diri dari pergaulan) tergantung pada intensitas dan frekuensi dari KSA yang terjadi pada korban. Lipovsky dan Kilpatrick (1992) menemukan bahwa KSA dapat mencederai kondisi emosional psikologis dan kesehatan fisik. Cedera emosi dan perilaku dapat menimbulkan gangguan yang signifikan pada perkembangan anak dan seringkali berdampak selamanya, yang mengarah kepada disfungsi dan stres saat memasuki masa dewasa. Konsekuensi KSA tidak terbatas pada korban tetapi juga berpengaruh kepada masyarakat secara keseluruhan (Freyd et al., 2005).

Dampak negatif yang ditimbulkan KSA begitu besar, maka seharusnya dilakukan upaya pencegahan terjadinya KSA. Pencegahan primer diperlukan untuk meminimalisasi kasus KSA. Menurut Anderson, Mangels, dan Langsam (2004), tujuan prevensi primer adalah untuk mencegah terjadinya KSA dengan cara memberikan edukasi pada anak, orang tua, dan komunitas. Hal ini merupakan saat yang baik bagi orang dewasa untuk berkontribusi dalam melindungi anak-anak dan menciptakan lingkungan yang aman dengan mengimplementasikan intervensi pencegahan melalui guru, orang tua, dan praktisi (Kenny \& Wurtele, 2008). Hal ini mencerminkan pendekatan interdisipliner 
yang memiliki potensi besar menjaga anak-anak agar aman dari ancaman KSA (Friedman, 2010). Dasar prevensi dan intervensi kasus-kasus penyimpangan individu, yaitu: (1) meningkatkan kekuatan individu (increasing individual strengths) dan mengurangi kelemahan individu (decreasing individual limitation), (2) meningkatkan dukungan sosial (increasing social support) dan mengurangi tekanan sosial (decreasing social stresses), dan (3) meningkatkan kemudahan yang ditimbulkan dari lingkungan fisik dan mengurangi kesulitan yang ditimbulkan dari lingkungan fisik (Bloom, 1996). Tujuan kegiatan adalah membangun gerakan kepedulian masyarakat terhadap perlindungan anak dari ancaman Kekerasan Seksual pada Anak (KSA) melalui orang tua siswa TK.

Semakin bertambahnya kasus KSA di kota Jember semakin penting pencegahan harus dilakukan karena jika dibiarkan maka akan semakin meluas dan memperparah kondisi kesejahteraan anak di Jember dan sekitarnya. Dengan demikian semakin urgen diseminasi tentang kasus KSA di kota ini. Dampak jangka pendek maupun panjang dan pencegahan dimulai dari keluarga, berlanjut ke lingkungan keluarga dan komunitas dalam skala kecil (RT/RW). Terbentuknya KAKSA orang tua yaitu komunitas anti kekerasan seksual pada anak oleh orang tua di sekitar kota Jember yang peduli dengan hak-hak anak termasuk perlindungan terhadap KSA diharapkan dapat mengurangi kasus KSA di kota Jember.

\section{Metode}

Pelaksanaan program "KAKSA orang tua" meliputi penentuan subjek orang tua, pelatihan, pengambilan data melalui pengisian kuesioner pengetahuan, penyebaran informasi terkait KSA kepada masyarakat oleh KAKSA orang tua, dan diskusi. Program dilakukan di wilayah kerja Kota Jember mencakup pertemuan sosialisasi, pelatihan, pertemuan tindak lanjut, dan kegiatan promosi kesehatan oleh KAKSA orang tua.

Pelaksanaan sosialisasi dilaksanakan di aula prodi PAUD Universitas Negeri Jember, pihak yang terlibat adalah peneliti, orang tua siswa TK, dan pihak prodi PAUD. Orang tua siswa TK yang hadir sebanyak 26 orang. Hasil dari pertemuan ini disepakati pembentukan KAKSA orang tua, waktu pelaksanaan pelatihan, tempat pelatihan, dan fasilitas selama pelatihan. Pertemuan prapelatihan dilaksanakan 1 minggu setelah pertemuan sosialisasi. Orang tua siswa TK yang hadir sebanyak 26 orang. Pada pertemuan ini dilaksanakan pretes yaitu pengisian kuesioner pengetahuan KSA (pretes) dan informed consent.

Hasil dari pertemuan tindak lanjut ini adalah rencana promosi kesehatan kepada masyarakat tentang KSA dengan rincian yaitu terbentuknya kelompok KAKSA orang tua siswa TK, penentuan sasaran, dan waktu pelaksanaan program. Sasaran dari program ini adalah orang tua siswa TK yang memiliki balita sebagai bentuk prevensi KSA. Maka orang tua diharapkan berpartisipasi ketika dilaksanakn program Posyandu karena

Tabel 1.

Hasil Statistik Deskriptif

\begin{tabular}{cccc}
\hline Waktu Pengukuran & Rerata & SD & N \\
\hline Pretes & 63,54 & 3,73 & 26 \\
Postes & 65,62 & 2,58 & 26 \\
\hline
\end{tabular}


program Posyandu menyediakan waktu untuk psikoedukasi prevensi KSA. Masukan lain dari orang tua bahwa program ini dapat juga dilakukan di kegiatan lain sebagai alternatif yaitu pada kegiatan bina keluarga balita dan arisan. Dengan pertimbangan peserta bina keluarga balita juga merupakan ibu yang memiliki balita. Sedangkan pemberian psikoedukasi di arisan dipilih orang tua karena arisan sering menjadi media penyebaran informasi. Berdasarkan masukan tersebut, maka disepakati bahwa program psikoedukasi dilakukan saat kegiatan posyandu, bina keluarga balita, atau arisan.

\section{Hasil}

Program ini dilakukan di wilayah kerja kota Jember. Jumlah subjek yang mengikuti penelitian adalah 26 orang tua siswa TK. Hasil uji pengetahuan KAKSA orang tua siswa TK menunjukkan bahwa rerata skor pengetahuan saat pretes adalah 63,54 kemudian menjadi 65,62 saat postes.

Nilai standar deviasi pada saat pretes $(S=3,73)$ lebih besar dibanding postes $(S=2,58)$, hal ini menunjukkan bahwa skor pengetahuan pada kelompok subjek saat pretes lebih bervariasi dibanding saat postes. Skor pengetahuan saat pretes menunjukkan nilai paling rendah yaitu 53 dan paling tinggi 69, sedangkan skor pada postes bergerak dari nilai 59 hingga 68. Skor pengetahuan saat pretes-postes berbeda signifikan $(p<0,05)$ dengan perubahan skor pengetahuan dari pretes ke postes sebesar -2,97, artinya skor pengetahuan saat postes lebih tinggi dibanding pretes. Artinya program prevensi KSA dapat meningkatkan pengetahuan orang tua siswa TK tentang KSA. Oleh karena nilai $r=0,38$ dan $p<0,05$ artinya terdapat hubungan antara pengetahuan KSA sebelum dan sesudah interensi. Demikian juga sumbangan psikoedukasi terhadap peningkatan pengetahuan tentang KSA adalah r=0,409 kuadrad atau sama dengan 0,17 (17\%) sehingga terdapat $83 \%$ disebabkan oleh faktor yang lain. Pelatihan KSA cukup efektif untuk mengubah struktur kognitif dan menyediakan kesempatan untuk mendapatkan pengetahuan (Johnson \& Johnson, 2001; Hunt, 2003).

\section{Diskusi}

Guna mendapatkan data yang lebih kaya, peneliti juga melakukan wawancara terhadap subjek penelitian. Hasil wawancara berikut mengungkapkan pendapat $\mathrm{Hal}$ ini diungkapkan pula oleh subjek saat wawancara:

“Jadi membuka mata. Jadi tahu oh ini yang untuk kasus-kasus yang merebak. Jadi lebih tahu. Semoga dengan pelatihan jadi berkurang kasus-kasus yang merebak."

Secara lebih rinci diungkapkan orang tua bahwa program prevensi KSA menambah pengetahuan terkait anggota tubuh yang tidak boleh sembarangan disentuh dan berbagai jenis KSA, seperti tercermin dalam pernyataan berikut,

“...misalnya kalau saya mandiin kan pegang alat kelaminnya nah "mbah ojo di pegang-pegang, nggak boleh itu'. Iya, lah kan awalnya saya mikir, 'lah ngopo nggak boleh kan bersihin'. Oh ternyata setelah saya ikut pelatihan kemaren itu oh iya ada bagian tubuh yang memang nggak boleh sembarangan dipegang..."

"Kalau buat ibu sih ya jadi tahu kekerasan itu ya nggak cuma perkosaan yo ternyata nyentuhnyentuh gitu tu termasuk. gitu tho? Di bagian-bagian tertentu. Yo kayak 
mangku-mangku bocah trus ngelusngelus paha yo udah menjurus."

Hasil tersebut juga didukung oleh respons orang tua saat menjawab pertanyaan terbuka terkait evaluasi program. Subjek memaparkan bahwa program psikoedukasi prevensi KSA menjadi sebuah tambahan ilmu untuk mendidik anak, harus disebarkan di lingkungan wilayahnya, dan sangat bermanfaat bagi orang tua karena orang tua adalah orang pertama di keluarga yang mengetahui setiap kasus di lingkungannya.

Pentingnya program ini juga diungkap oleh seorang orang tua yang mengatakan bahwa pelatihan menjadi syarat sebelum orang tua dapat melakukan tugasnya yaitu sosialisasi kepada warga. Orang tua tersebut mengatakan bahwa melalui pelatihan menjadikan tambahan ilmu, pernyataan ini terungkap sebagai berikut,

“...Yo orang tua yang berperan dalam hal sosialisasi misalnya disosialisasi lewat arisan kui atau rapat RT, PKK, RW tapi dengan syarat tokoh masyarakat dan kader ikut pelatihan dulu tentang KSA nah tindak lanjute ya ditularkan lagi ke orang lain, ya orang tua anak yo mba. Jadi orang tua harus punya pengetahuan tentang KSA dulu. Yo misale orang tua ora ono ilmu yo arep ngandani opo tho..."

Ungkapan orang tua tersebut menunjukkan pentingnya memiliki pengetahuan sebelum melakukan tugas sebagai agen pengubah. Hal ini sesuai dengan penelitian Lopez, Tjokrosanto, \& Paramastri (2004) tentang promosi kesehatan bahwa seseorang yang memiliki pengetahuan dan keterampilan akan lebih mudah dalam melaksanakan tugas dan tanggung jawab yang diemban.

Tahapan selanjutnya setelah orang tua mendapat program yaitu promosi kesehatan tentang prevensi KSA kepada masyarakat di sekitar tempat tinggalnya. Promosi kesehatan dirancang sebagai usaha KAKSA orang tua sebagai agen prevensi KSA. Aktivitas ini didukung oleh para orang tua lainnya, terbukti dengan adanya respons orang tua pada lembar evaluasi. Orang tua menuliskan bahwa siap menginformasikan ke posyandu tentang KSA sebagai bentuk prevensi KSA. Aktivitas promosi kesehatan dilakukan disesuaikan dengan aktivitas orang tua di lingkungan.

KAKSA orang tua sudah memahami bahwa mensosialisasikan informasi yang didapat dari program-program yang diikuti orang tua baik program Puskesmas, Kelurahan, Kecamatan, ataupun Kota adalah tugas orang tua. Maka, orang tua yang tergabung dalam KAKSA bersedia melakukan promosi kesehatan tentang pencegahan KSA kepada warga di lingkungannya. Hal tersebut juga dipengaruhi oleh kondisi lingkungan tempat tinggal orang tua seperti terungkap pada kutipan wawancara tentang kejadian KSA di lingkungan tempat tinggal orang tua, sebagai berikut,

“...yang anak cewe kan disuruh itu lho mba oral yang anak laki-laki. Padahal masih paud lho mba. Yang perempuan itu masih TK kecil, ... yang laki-laki itu TK besar...."

Selain itu, berdasarkan wawancara dengan para KAKSA orang tua menyebutkan bahwa di area menuju tempat wisata di Jember terdapat "gubuk deret" sebagai tempat kencan para remaja. Hal ini tampak dari sepatu pria \& wanita, helm dan sepeda motor di depat "gubuk deret". Berdasarkan observasi tim peneliti memang hampir semua "gubuk deret" terisi dan hal ini dibuktikan dengan 
wawancara tim peneliti dengan penjual minuman (pemilik warung) di sekitar "gubuk deret" yang mengatakan bahwa beberapa kali dijumpai remaja yang membawa anak berkencan di tempat tersebut.

Sesungguhnya pihak Dinas Kesehatan setempat sudah melakukan promosi kesehatan pencegahan KSA melalui ceramah di berbagai lapisan masyarakat, tetapi realitanya masih saja terjadi KSA. Oleh karena itu pembentukan KAKSA orang tua ini dirancang untuk diterapkan mulai dari level yang paling mikro yaitu RT yang selanjutnya meluas sampai ke level RW. Berdasarkan kesepakatan KAKSA orang tua, mereka akan menerapkan pada lima RT terlebih dahulu, dengan memberikan ceramah dan liflet kepada warga RT. Setelah menyasar ke RT selanjutnya melebar ke warga RW.

Sasaran dari promosi kesehatan ini adalah warga yang masih memiliki balita. Maka promosi kesehatan dilakukan saat posyandu. Namun, ada saran dari orang tua bahwa penyampaian informasi KSA juga dapat dilakukan saat acara BKB (Bina Keluarga Balita) karena pesertanya adalah ibu yang memiliki balita. Saran lain adalah penyampaian informasi saat arisan karena arisan juga menjadi wadah untuk penyebaran informasi. Saat arisan, peserta yang hadir tentu saja berasal dari warga yang lebih luas, tidak selalu ibu yang memiliki balita meskipun begitu peneliti memperbolehkan tetapi pemberian kuesioner hanya untuk ibu yang memiliki balita.

Pada saat kegiatan ceramah, tiga orang kader mengikuti cara-cara yang dilakukan oleh fasilitator saat pelatihan di Puskesmas. Ketika pelatihan, fasilitator menggunakan beberapa pendekatan sesuai dengan modul pelatihan. Pendekatan yang dicontoh oleh kader yaitu metaplan. KAKSA orang tua membagikan kertas kosong pada beberapa peserta ceramah dan meminta peserta untuk mengungkapkan hal yang mereka ketahui tentang KSA. KAKSA orang tua mengelompokkan jawaban peserta ke dalam kategori-kategori topik pembahasan KSA. Pendekatan lain yaitu pemberian pertanyaan pada selembar kertas yang kemudian diisi peserta ceramah untuk menjadi bahan diskusi. Para KAKSA orang tua berinisiatif memutar film pendek dari unggahan youtube tentang sentuhan yang boleh dilakukan dan sentuhan yang tidak boleh dilakukan.

Perilaku tersebut merupakan hasil dari proses belajar saat pelatihan. Selain menyerap materi pelatihan, KAKSA orang tua juga mengamati fasilitator dalam menyampaikan materi. Pembelajaran dapat terjadi dengan cara praktik melalui tindakan yang sebenarnya atau dapat dengan cara mengamati model-model yang melakukannya (Schunk, 2012). Hal yang dilakukan oleh KAKSA orang tua ketika ceramah merupakan hasil dari proses mengamati model. Bandura (1986) memaparkan bahwa mengamati orang lain merupakan hal yang penting dalam proses pembelajaran. Melalui tindakan mengamati orang lain, individu mempelajari hal baru melalui observasi. Observasi dilakukan dengan mengamati perilaku model (fasilitator) sehingga dapat menghasilkan perilaku serupa.

Proses pembelajaran observasional mencakup empat proses yaitu perhatian, retensi, produksi perilaku, dan motivasi (Bandura, 1986). Proses pertama, KAKSA orang tua memberikan perhatian terhadap model (fasilitator). Karakteristik model dapat memengaruhi perhatian pengamat. Maka, fasilitator dalam pelatihan haruslah orang yang kompeten dalam hal ini adalah orang yang terbiasa menjadi fasilitator dan mengerti terkait KSA. Proses kedua adalah retensi. Retensi dapat ditingkatkan dengan cara mengulang informasi 
maupun pengkodean (Schunk, 2012). Pada tahap ini, pengamat mengingat urutan aktivitas-aktivitas yang dilakukan oleh model. Tahap ketiga adalah produksi yaitu melakukan tindakan nyata. Proses produksi ini terlihat ketika kader melakukan ceramah. Saat ceramah urutan kegiatan seperti yang terjadi ketika pelatihan yaitu diawali dengan metaplan dan di akhir ceramah diperlihatkan film pendek. Proses keempat adalah motivasi. Pengamat mempraktikkan tindakan yang mereka yakini dapat memberikan hasil positif dan menghindari tindakan yang memberikan hasil negatif. KAKSA orang tua yakin bahwa materi tentang pencegahan KSA dapat memberikan manfaat pada warga. Harapan ini menggerakkan para orang tua untuk melakukan sosialisasi. Namun ada kekhawatiran pada diri KAKSA orang tua yaitu ketika ceramah, mereka tidak dapat menjawab pertanyaan warga. Hal ini disiasati oleh KAKSA orang tua dengan meminta ditemani oleh peneliti saat melakukan ceramah.

Harapan-harapan yang diungkap kader di antaranya anak-anak dapat terhindar dari KSA dan materi ceramah dapat menjadi pembelajaran bagi para ibu.

"Yo bisa jadi pembelajaran bagi warga kalau dia nya nyambung ...Ya sing tak harapke yo ono kayak kuwi yo dirungoke jadi kalau ono kejadian apaapa meh iso dicegah. Misale yo nganggapne saru tapi ada acara ini kan jadi ora isin-isin. "Oh iyo yo ternyata ora ngisin-ngisini".

Selain KAKSA orang tua mencontoh aktivitas yang dilakukan oleh fasilitator ketika pelatihan dan menerapkannya ketika sosialisasi. Orang tua juga menyadari bahwa mereka juga menjadi contoh bagi warga sekitar, sehingga orang tua mempraktekkan perilaku yang mereka yakini akan memberikan dampak pofitif bagi warga. Hal tersebut diungkap orang tua dalam wawancara.

"Jadi kader itu berat lho mba. Kita ngasih penyuluhan in itu tapi kitanya sendiri juga nggak kayak gitu ya gimana ya...lebih jadi contoh...Kita usahakan ada perbaikan ya. Kalau ngubah total kan ya susah. Ada warga yang susah dikasih tahu, ya nggak tahu tapi kayak yang tahu ngono lah mba."

"Yo sajane abot sih mba jadi orang tua iku. Yo kerja sosial kadang makan hati... Tapi ya ibu seneng sih buat anakanak kita juga. Harus jadi contoh juga. Ya dulu ibu itu ngomongnya kasar ya sekarang jadi dihalus-haluske. Kalau ada orang tua anak yang protes gimana "kok koyok ngono". Jadi masyarakat bisa ngebalikin ke kitanya. Jadi ibu ya "oh iya ya kudu koyok ngene". Nah iya itu tantangannya jadi orang tua begitu. Jadi sekarang ibu ya hati-hati kalau mau apa-apa."

Ceramah menjadi metode favorit dalam melakukan psikoedukasi prevensi KSA. KAKSA orang tua menganggap ceramah sebagai metode yang mudah, hemat waktu, dan hemat biaya. Ceramah dapat dilakukan baik secara formal maupun nonformal. Hal tersebut menjadi kelebihan metode ceramah. Meskipun begitu, orang tua menyadari bahwa ceramah memiliki kekurangan terkait respons dari masyarakat. KAKSA orang tua tidak yakin bahwa masyarakat benarbenar memahami apa yang disampaikan dalam ceramah. Kendala lain yang dihadapi orang tua ketika ceramah adalah warga tidak begitu memperhatikan apa yang disampaikannya. Hal tersebut diungkap orang tua sebagai berikut.

“...Kan kita harus interaktif ya kalau ke 
warga. Iya bisa dengan cara-cara yang tadi itu, lebih person mba. Lebih personal gitu mba kayak 'itu anakmu gini gini'. Nggak selalu harus di forum supaya nggak kaku. Kalau personal jadi lebih santai dan terbuka. Kan yang diperlukan keterbukaan itu. Kadangkadang kalau meneng ae kan jadi bertanya-tanya ini dong opo ora." "Jadi ya mbuh ngerti mbuh ora ya yang penting ibu udah ngomong. Yang penting ibu udah membagi apa yang udah didapet dari pelatihan di puskesmas...Kalau ke ibu-ibu ya kadang suka ngomong dewe. Ya kadang denger tapi yo mbuh diterapke di kehidupan mereka opo ora....".

KAKSA orang tua berpendapat bahwa media leaflet adalah media yang memerlukan biaya. leaflet akan sulit diterapkan pada warga yang tidak suka membaca. Namun, leaflet dapat menjadi alternatif ketika orang tua merasa sungkan untuk melakukan penyuluhan secara lisan pada tetangganya, misalnya pernyataan berikut ini.

“...Ya lisan mba. Ya kalau pakai macam-macam kayak selebaran gitu yo duite sopo. Harus fotokopi segala. Ya pakai uang siapa. Ya paling enak ceramah. Nggak harus di acara formal juga mba, bisa pas lagi santai-santai. Enak itu mba bisa kapan aja, hemat biaya.".

“...tapi mba, masyarakat di sini itu lebih susah kalau pakai selebaran begitu, rata-rata sedikit yang suka baca. Mereka lebih suka denger, duduk, diam, pulang. Tapi untuk orang-orang yang susah dikasih tahu langsung atau jarang datang ke acara-acara nah itu bisa jadi alternatif..."

KAKSA orang tua mengalami peningkatan paling banyak pada aspek rehearsal. Miltenberger (2008) menjelaskan bahwa rehearsal adalah prosedur pemberian kesempatan kepada anak untuk melatih perilakunya setelah mendapatkan contoh dan petunjuk dari model. Sebelum mengikuti pelatihan, subjek tidak memberikan kesempatan orang tua untuk melatih perilaku sesuai dengan yang dicontohkan oleh fasilitator saat mengajarkan keterampilan perlindungan diri. Padahal aspek rehearsal sangat penting dalam pembelajaran behavioristik (Johnston, 2010), karena fasilitator dapat lebih mengetahui apakah kader telah menguasai keterampilan sesuai dengan yang diajarkan. Dengan memberikan kesempatan kader untuk praktik juga menciptakan kesempatan untuk mendapatkan umpan balik. Penelitian menunjukkan bahwa semakin banyak subjek mendapatkan kesempatan memperoleh umpan balik yang positif dari perilaku yang ditunjukkan, maka semakin subjek termotivasi untuk menunjukkan perilaku secara tepat sesuai dengan yang dimodelkan (Cooper, Heron, dan Heward, 2007).

Berdasarkan teori sosial kognitif, perilaku bukannya refleks, tetapi merupakan akibat interaksi antara lingkungan dengan skema kognitif (Bandura, 1986). Peningkatan keterampilan mengajar prevensi KSA merupakan akibat dari peningkatan pengetahuan prevensi KSA dan keterlibatan kader posyandu dalam pelatihan. Para kader posyandu menerima pengetahuan mengenai KSA, faktor risiko, perlindungan diri, dan keterampilan mengajar prevensi KSA. Para kader posyandu juga diajak untuk melakukan roleplay cara mengajarkan keterampilan perlindungan diri dari KSA. Proses pembelajaran dalam program ini menggunakan teknik observational learning memungkinkan kader posyandu belajar 
dari proses mengamati orang lain. Dengan demikian, terdapat interaksi antara orang tua (faktor personal) dengan orang lain (faktor lingkungan), yang yaitu peserta yang lain, fasilitator, materi, leaflet, dan film. Faktor lingkungan ini memengaruhi orang tua melalui berbagai aktivitas misalnya ceramah, diskusi, liflet, dan roleplay.

Proses observational learning dalam pelatihan dicapai melalui empat tahapan proses pembelajaran yaitu attentional processes, retention processes, production processes, dan motivational processes (Bandura, 1986). Penggunaan metode pelatihan dan observational learning terbukti dapat memberikan sumbersumber infomasi prevensi KSA sehingga dapat meningkatkan keterampilan mengajar prevensi KSA (Islawati, 2014; Supardi, 2014). Keempat tahapan pembelajaran observational learning teraplikasi pada setiap sesi pelatihan sehingga hal ini jugalah yang memengaruhi peningkatan keterampilan kader posyandu.

Keberhasilan pelatihan dalam meningkatkan keterampilan orang tua dalam pencegahan KSA didukung oleh berbagai faktor, yaitu landasan teori yang digunakan. Keterampilan mengajar prevensi KSA dalam penelitian ini menggunakan pendekatan perilaku. Dasar-dasar keterampilan tersebut mengacu pada teknik mengajar behavioristic yaitu behavior skill training yang terdiri dari empat aspek yaitu modeling, instruction, rehearsal, dan feedback (Miltenberger, 2008). Selain itu juga penggunaan metode belajar observational learning. Metode ini memungkinkan orang tua belajar dari proses mengamati orang lain. Artinya, terdapat interaksi antara orang tua (faktor personal) dengan orang lain (faktor lingkungan), misalnya kader posyandu, fasilitator, booklet, materi, leaflet. Metode belajar ini memungkinkan orang tua belajar langsung dari model sehingga proses pembelajaran lebih efisien (Bandura, 1986; Schunk, 2012).

\section{Kesimpulan}

Program KAKSA orang tua sebagai bentuk program pencegahan KSA bermanfaat untuk meningkatkan pengetahuan orang tua siswa TK tentang pencegahan KSA.

\section{Saran}

Berdasarkan evaluasi, para KAKSA orang tua siswa TK menyatakan mendapatkan manfaat dari pelatihan yang telah dilakukan terutama dalam pengetahuan mengenai KSA. Para orang tua siswa TK juga menyatakan bahwa fasilitator cukup ramah, sopan, mudah diterima, dan dipahami. Beberapa usulan dari para orang tua yaitu; penataan ruangan supaya lebih rapi, adanya penambahan alokasi waktu pelatihan, dan sekiranya perlu diadakan kembali pelatihan serupa agar para orang tua yang lainnya (berbeda RT \& RW) mendapatkan manfaat yang sama.

\section{Daftar Pustaka}

Anderson, J. F., Mangels, N. J., \& Langsam, A. (2004). Child sexual abuse: A public health issue. Criminal Justice Studies, 17, 107-126. doi: $\underline{10.1080 / 08884310420001679386}$

Bandura, A. (1986). Social foundations of thought and action: A social cognitive theory. Englewood Cliffs, New Jersey: Prentice Hall.

Badan Pemberdayaan Perempuan dan Masyarakat (2016). Data gender dan anak Daerah Istimewa Yogyakarta (Annually). Daerah Istimewa Yogyakarta: BPPM. Diunduh dari http://dl.dropboxusercontent.cm/u/ 100717025/Buku\%20Data\%20Pilah\% 20Tahun\%202016.pdf. 
Bloom, M. (1996). Primary prevention practices. Issues in children's and families lives. Thousand Oaks, California: SAGE publication

Butchart, A., \& Mikton, C. (2014). Global status report on violence prevention 2014. Geneva, Switzerland: World Health Organization.

Children's Bureau. (2016) Definitions of child abuse and neglect. Diunduh dari https://www.childwelfare.gov/pubP DFs/define.pdf.

Cooper, J. O., Heron, T. E., \& Heward, W. L. (2007). Applied behavioral analysis (Second Edition). London: Pearson.

Filkelhor, D. (2005). The victimization of children and youth: A omprehensive national survey. Journal of Child Maltratment 10(1), 5-25. doi: $\underline{10.1177 / 1077559504271287}$

Friedman, N. E (2010). Child sexual abuse prevention: Critical role of parents. Camping Magazine, 46- 52.

Freyd, J. J., Putnam, F. W., Lyon, T. D., Becker-Blease, K. A., Cheit, R. E., Siegel, N. B., \& Pezdek, K. (2005). The Science of Child Sexual Abuse. Science, 308(5721), 501. doi: 10.1126/science.1108066

Gaskill, R. L \& Perry, B. D (2012). Child sexual abuse, traumatic experiences, and their impact on the developing brain. In Brown (Ed), Handbook of Child Sexual Abuse (Identification, Assessment and Treatment), (pp. 2947). US: John Wiley \& Sons, Inc.

Goodyear-Brown, P. (Ed). (2012). Handbook of child sexual abuse: identification, assessment, and treatment. Hoboken: Wiley

Islawati, I., 2014. Program "Jari Peri" untuk meningkatkan efikasi guru SD dalam mengajarkan prevensi kekerasan seksual pada anak (Tesis master tidak dipublikasikan). Yogyakarta: Universitas Gadjah Mada.

Johnston, M. (2010). Teaching sexual abuse prevention skills through game play. Thesis, Ontario: Centre for Applied Studies, Brock University.

Kenny, M. C. \& Wurtele, S. K. (2008). Toward prevention of chilhood sexual abuse: Preschoolers' knowledge of genital body parts. In Plakhtonik \& S. M. Nielsen (Eds), Proceedings of Seventh Annual College of Education Reseach Conference: Urban and International Education Section ( $p p$, 74-79). Miami: Florida International University. http://coeweb.fiu.edu/research conf erence/

Komnas Perempuan. (2016). Lembar fakta catatan tahunan (Catahu) 2016 kekerasan terhadap perem puan meluas: Mendesak negara hadir hentikan kekerasan terhadap perempuan diranah domestik, komunitas dan negara. Diunduh dari http://www.komnasperempuan. go.id/wpcontent/uploads/2016/03/LembarFakta-Catatan-Thunan-CATAHUKomnas-Perem puan-2016.pdf

Lipovsky, J. A. \& Kilpatrick, D. G. (1992) The child sexual abuse victim as an adult. In W. O'Donohue \& J. H. Geer (Eds.). The sexual abuse of children: Clinical issues. 2. Hillsdale, New Jersey: Lawrence Erlbaum Associates.

Lopez, P. Y., Tjokrosonto, S., \& Paramastri, I. (2004). Promosi kesehatan pada kader posyandu dalam meningkatkan pengetahuan dan keterampilan tantang penanggulangan malaria di kabupaten Timor Tengah Utara. Sains Kesehatan, 17(1), 77-87.

Miltenberger, R. G. (2008). Behavior modification: Principles and procedures. Fourth Edition, USA : Thomson Higher Education.

Schunk, D. H. (2012). Teori-teori 
pembelajaran: Perspektif pendidikan (Terjemahan: Eva Hamdiah \& Rahmat Fajar). Edisi keenam. Yogyakarta: Pustaka Pelajar.

Supardi, J. S. (2014). Validasi modul "JARI PERI" untuk meningkatkan keterampilan pengajar sektor nonformal dalam mengajarkan pencegahan KSA (Tesis master tidak dipublikasikan). Yogyakarta: Magister Psikologi Universitas Gadjah Mada.
United Nations \& United Nations (Eds.) (2009). Pacific perspectives on the commercial sexual exploitation and sexual abuse of children and youth. Bangkok: United Nations ESCAP.

World Health Organization. (2016). Child maltreatment. Fact sheet. Reviewed September 2016. World Health Organization. Diunduh dari http://www.who.int/mediacenter/fa ctsheets/fs150/en/ 